INTERACTION OF

METALS AND GASES 


\title{
INTERACTION OF METALS AND GASES
}

\author{
Vol. 2
}

Kinetics and Mechanisms

\author{
J. D. FAST \\ Chief Metallurgist Philips Research Laboratories \\ and Professor at the Technical University of Eindhoven
}


English edition (C) N. V. Philips' Gloeilampenfabrieken, Eindhoven, 1971

Softcover reprint of the hardcover 1st edition 1971 978-0-333-07564-7

All rights reserved. No part of this publication may be reproduced or transmitted in any form or by any means, without permission.

SBN 333075641

ISBN 978-1-349-00502-4 ISBN 978-1-349-00500-0 (eBook)
DOI 10.1007/978-1-349-00500-0

First published by

MACMILLAN PRESS LTD.

London and Basingstoke

Associated companies in New York, Toronto, Melbourne, Dublin, Johannesburg and Madras

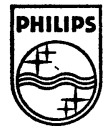

\section{PHILIPS}

Trademarks of N. V. Philips' Gloeilampenfabrieken 


\section{PREFACE}

Like the first volume of 'Interaction of Metals and Gases' this second volume with the sub-title 'Kinetics and Mechanisms' handles the theoretical background as simply as possible. It has been written for metallurgical students, industrial metallurgists and chemists. Three subjects have been omitted from the book, those of adsorption, catalysis and oxidation, not because they are unimportant but rather because they are so all-important that a large number of excellent books are already devoted to them. Consequently this volume, with the exception of Section 4.12, deals exclusively with the behaviour of gases in the interior of metals, leaving interactions with metal surfaces out of consideration. 


\section{CONTENTS}

Chapter 1. Solutions of Gases in Metals

1.1. Foreign interstitial solute atoms in metals 1

1.2. Size of the interstices 3

1.3. Effect of the size factor 7

1.4. Redistribution of interstitial atoms following lattice distortion 15

1.5. Electronic interaction 21

1.6. Chemical factors 24

1.7. Brillouin zones and energy bands 27

1.8. Fermi surface and electronic specific heat 36

1.9. Hydrogen in palladium 39

1.10. Hydrogen in palladium alloys 48

1.11. Hydrogen in nickel 64

1.12. The nature of bonding in transition-metal hydrides 73

1.13. Confrontation of proton theory and anion theory $\quad 79$

1.14. Oxygen in transition metals and in transition-metal alloys

Chapter 2. Diffusion in Interstitial Alloys

2.1. Introduction 88

2.2. Steady-state diffusion 88

2.3. Non-steady-state diffusion 92

2.4. Measurement of diffusivities of gases in metals 97

2.5. Dependence of diffusivity on concentration 100

2.6. Concentration and chemical potential 108

2.7. The statistical nature of diffusion 112

2.8. Atomic and macroscopic treatment of diffusion problems 116

2.9. Interstitial diffusion in fcc and bcc metals $\quad 120$

2.10. The influence of temperature 123 
2.11. The value of $D_{0}$ for the diffusion of hydrogen

2.12. The entropy of activation for interstitial diffusion 132

2.13. Diffusion of hydrogen in iron 133

2.14. Diffusion of carbon in iron 142

2.15. Diffusion along grain boundaries and dislocations 148

Chapter 3. Internal Friction of Metals

3.1. Introduction 159

3.2. Relaxation and hysteresis $\quad 159$

3.3. Relaxation caused by phonons and electrons 164

3.4. Relaxation associated with grain boundaries $\quad 166$

3.5. The Snoek effect 169

3.6. Relaxation due to interstitial atoms in fcc alloys 171

3.7. Relaxation due to reorientation of pairs of point defects 174

3.8. More about relaxation due to pairs of point defects 175

3.9. The Zener relaxation 179

3.10. Relaxation associated with dislocations 181

3.11. Hysteresis due to dislocations 184

3.12. Hysteresis due to domain walls 189

Chapter 4. The Snoek Effect and its Significance for Metal-Gas Problems

4.1. Relaxation time 195

4.2. Compliance 196

4.3. Time-dependent fields or stresses: derivation of the Debye equations

4.4. Derivation of the Debye equations without recourse to complex variables

4.5. The significance of the Debye equations for the Snoek effect

4.6. Checking the elementary theory with experimental data

4.7. Thermodynamic considerations

4.8. Relations between measures of internal friction

4.9. Determination of diffusivities of interstitial atoms

4.10. Determination of solubilities 
4.12. Study of surface reactions 236

4.13. Analytical determination of small quantities of carbon and nitrogen in iron

4.14. Interaction of interstitial atoms

4.15. Study of the kinetics of precipitation

4.16. Interaction between interstitial and substitutional atoms

4.17. Interaction between interstitial and substitutional atoms in the presence of a precipitate

4.18. Influence of quantum effects on diffusion

Chapter 5. INTERACTION OF INTERSTITIALS AND OTHER LATTICE IMPERFECTIONS

5.1. Interaction of foreign interstitials and dislocations 271

5.2. Yield point and strain-ageing 276

5.3. Segregation and precipitation 280

5.4. Exchange of solutes at dislocations 281

5.5. The cold-work peak 285

5.6. Interaction of interstitials and grain boundaries 292

5.7. Interaction of interstitials and domain boundaries 295 